\title{
DOI: 10.5846/stxb201302270319
}

宗盛伟,许嘉巍, 吴正方,乔琳琳,王丹丹,孟祥君,杜海波,王雷,王丹,王鹏,敖小龙,夏毓璘,吴福梅.长白山西坡小叶章侵人苔原带过程及影响. 生态学报,2014,34(23):6837-6846.

Zong S W, Xu J W, Wu Z F, Qiao L L, Wang D D, Meng X J, Du H B, Wang L, Wang D, Wang P, Ao X L, Xia Y L, Wu F M.Analysis of the process and impacts of Deyeuxia angustifolia Invasion on the Alpine Tundra, Changbai Mountain. Acta Ecologica Sinica,2014,34(23):6837-6846.

\section{长白山西坡小叶章侵入苔原带过程及影响}

\author{
宗盛伟 ${ }^{1}$, 许嘉巍 ${ }^{1, *}$, 吴正方 ${ }^{1}$, 乔琳琳 ${ }^{1}$, 王丹丹 ${ }^{1}$, 孟祥君 ${ }^{1,2}$, 杜海波 ${ }^{1}$, \\ 王 雷 ${ }^{1}$, 王 丹 $^{1}$, 王 鹏 ${ }^{1}$, 敖小龙 ${ }^{1}$, 夏毓璘 ${ }^{1}$, 吴福梅 ${ }^{1}$ \\ (1. 东北师范大学城市与环境科学学院, 长春 130024 ; 2. 吉林财经大学工商管理学院, 长春 130024)
}

\begin{abstract}
摘要: 长白山西坡岳桦林带的草本植物 (以小叶章为代表) 侵人了苔原带, 形成了独特的植物人侵现象。在光谱及影像分析的 基础上,结合 GPS (Global Positional System) 定位技术,并依据小叶章与牛皮杜鹃的光谱差异及其反演的 NDVI (Normalized Difference Vegetation Index) 植被指数, 揭示小叶章侵人苔原带的过程; 通过对不同侵人时间、强度的斑块进行群落调查及土壤测 试,探究小叶章侵人苔原带的生态后果。结果显示小叶章侵人苔原带始于 20 世纪 80 年代后期, 由低海拔向高海拔推进,进人 21 世纪后逐渐形成了稳定的以小叶章为优势物种的植物群落结构。目前, 低海拔处的小叶章斑块经过多年扩张已连接成片, 而高海拔处的斑块正处于扩张的初期阶段。从生物多样性变化可以看出, 小叶章侵人苔原带导致植物群落多样性升高和物种 数量的增加, 苔原带原有的灌木数量明显减少, 草本植物逐渐增多。植被的改变影响了土壤的理化性质, $\mathrm{C} / \mathrm{N}$ 比下降, 土壤腐殖 质含量和全氮含量下降,但速效氮和土壤持水能力上升,土壤养分的高效利用又进一步推动了小叶章的侵人。小叶章侵人苔原 带已经造成了严重的生态后果。
\end{abstract}

关键词:小叶章;植物人侵;高山苔原带;长白山

\section{Analysis of the process and impacts of Deyeuxia angustifolia Invasion on the Alpine Tundra, Changbai Mountain}

\author{
ZONG Shengwei ${ }^{1}$, XU Jiawei ${ }^{1, *}$, WU Zhengfang ${ }^{1}$, QIAO Linlin ${ }^{1}$, WANG Dandan ${ }^{1}$, MENG Xiangjun ${ }^{1,2}$, DU \\ Haibo $^{1}$, WANG Lei ${ }^{1}$, WANG Dan ${ }^{1}$, WANG Peng ${ }^{1}$, AO Xiaolong ${ }^{1}$, XIA Yulin ${ }^{1}$, WU Fumei ${ }^{1}$ \\ 1 College of Urban and Environmental Sciences, Northeast Normal University, Changchun 130024, China \\ 2 Tourism Management, Jilin University of Finance and Economics, Changchun 130024, China
}

\begin{abstract}
In China, the alpine tundra of Changbai Mountain is one of only three areas in China with this type of rare alpine tundra. The vegetation has undergone significant change in recent decades. Herbaceous species from the 'Betula ermanii zone', represented by Deyeuxia angustifolia, have invaded the alpine tundra zone on Changbai Mountain. This incursion represents a unique phenomenon in the mountainous areas of China. We examined the incursion process of D. angustifolia using GPS (Global positional system) techniques based on spectral and image analysis. In the study area, GPS equipment was used to identify individual $D$. angustifolia patches. Spectral analysis, particularly the red edge bands, was conducted by comparing the hyperspectral data between the invasive D. andustifolia and the native species, Rhododendron chrysanthum. The spectral diversity of the invasive and native species' enabled us to compare their NDVI ( Normalized Difference Vegetation Index), which was used to analyze within patch changes in vegetation. Landsat TM images from 1983, 1999,

基金项目:国家自然科学基金资助项目 (41171038，41171072); 教育部博士点基金(20120043110014); 国家地震局行业专项 (201208005); 国家 大学生创新创业训练计划项目 (201210200088)

收稿日期: 2013-02-27; 网络出版日期: 2014-03- 18

* 通讯作者 Corresponding author.E-mail: xujw634@ nenu.edu.cn
\end{abstract}


2002, 2006 and 2008 were used to calculate the NDVI index. The results showed that the incursion of D. angustifolia began in the 1980s. Currently, D. angustifoliahas successfully invaded this alpine landscape with the gradual trend following an altitudinal gradient. The incursion range has extended from relatively low elevations to higher elevations. Moreover, the inference is that $D$. angustifolia patches at lower elevations are interconnected forming relatively large patches. At higher elevations in the tundra landscape, these D. angustifolia patches were smaller and more scattered. We also investigated the ecological consequences of the D. angustifolia invasion using plant community surveys and soil tests. The D. angustifolia patches were defined as patches at different times of invasion, which consisted of three different invasive levels (low, medium and high levels of invasion). In the newly formed plant community $D$. angustifolia was the dominant species. While this invasion altered the native plant community structure and enhanced biodiversity, it altered some soil properties including both physical and chemical properties. Compared with the native plant community, dominated by $R$. chrysanthum, the invasive patches showed higher Shannon-Wiener diversity and species richness. Changes in abundance and evenness of the community suggested that $D$. angustifolia would occupy the most dominate position in that community. The change of community structure resulted in the reduction of shrubs and increased the number of herbaceous species. The change of vegetation directly or indirectly led to changes in soil properties. The progression of invasion resulted in a decrease in the carbon/nitrogen ratio, soil humus and total nitrogen. However, the available nitrogen and soil water content increased. The changes in soil nutrients were closely related to changes in physical soil properties, especially for soil water content. The increases in soil water content altered nitrogen fixation processes, microbial decomposition and nitrification. We propose that the efficient use of soil nutrients may promote further D. angustifolia invasion. Moreover, we suggest that a time lag occurs between changes in the vegetation and soil properties. The invasion of $D$. angustifolia on the alpine tundra ecosystem has and continues to have severe impacts.

Key Words : Deyeuxia angustifolia; plant invasion; alpine tundra; Changbai Mountain

山地生态系统是响应气候及环境变化的敏感区 域。近年来, 受气候变化及人类活动干扰影响, 山地 生态系统的植被发生了很大的变化。低海拔植物向 高海拔地区侵入现象成为研究热点, 但大多表现为 树木或者灌木的上侵 ${ }^{[1]}$ 。草本植物侵人高海拔地区 的现象较为少见 ${ }^{[2]}$, Tsuyuzaki 和 Shiro 研究发现日本 $\mathrm{Usu}$ 火山喷发后的植被演替过程中, 湿生植物不是 来自于土壤种子库以及周边植物的繁殖, 而是来源 于山峰之外的低海拔生境 ${ }^{[3]}$; Wearne 和 Morgan 发现 了澳大利亚东部金雀儿草侵人亚高山植被现象, 认 为这是一种本地生态系统重构 ${ }^{[1]}$ 。在高山生态系统 中,一旦发生人侵现象, 将会产生严重后果, 包括物 种的灭绝、生态系统功能退化等 ${ }^{[4-6]}$ 。因此, 植物人 侵研究是保护高山地区生态系统安全的重要研究 领域。

长白山苔原带是我国仅有的三处高山苔原带之 一。目前, 青藏高原苔原带以及阿尔泰山苔原带未 见有植物上侵的研究报道, 而长白山苔原带的植被 变化一直令人瞩目。长白山北坡岳桦 (Betula ermanii Charm.) 上侵苔原带现象已经得到认同,并将 其归因于气候变暖的影响 ${ }^{[4]}$ 。然而与之对应的长白 山西坡苔原带未发现强烈的岳桦上侵, 且该地区的 植被变化鲜有人关注。钱家驹编写了长白山苔原带 植物名录 ${ }^{[5]}$, 钱宏对长白山苔原带植被进行了分类 调查 $^{[6]}$, 尚未涉及长白山西坡苔原带植被变化。然 而长白山西坡植被在 20 年间发生了巨大的变化, 1986 年台风过境之后, 长白山西坡岳桦林带产生了 风倒区,形成了大量的林窗, 这种干扰对于苔原带的 植被变化有着不可忽视的作用。另外, 经过文献分 析以及多年的野外实地调察, 发现西坡岳桦林下的 小叶章(Deyeuxia. angustifolia (Kom.) Y. L. Chang) 为代表的草本植物逐步侵人到海拔更高的苔原带, 形成与基质差异明显的斑块 ${ }^{[7]}$ 。从目前的植被分布 状况上看, 小叶章的分布范围已经覆盖了西坡苔原 带较大范围, 对于景观水平以及群落水平的影响十 分显著。针对小叶章侵人苔原带的研究已非常必 要, 其首要任务在于揭示侵人的演变过程以及对于 生态系统的影响。 
遥感,地理信息系统和全球定位系统 GPS 组成 的 $3 \mathrm{~S}$ 技术为植物侵人的过程研究提供了技术手段， 特别是在长时间序列的影像数据支持下。例如, Bradley 利用 Landsat Thematic Mapper(TM) 影像研究 了人侵植物对景观动态的影响 ${ }^{[8]}$; 近年来光谱技术 的应用主要在于区分本地植物与人侵植物的差异。 例如, Walsh 利用 EO-1 Hyperion 数据分析了人侵 植物的分布 ${ }^{[9]}$ 。高占国、张利权利用不同植物群落 的光谱差异, 为上海地区盐沼植被分类以及遥感监 测外来种互花米草的空间分布提供了影像解译的判 读依据 ${ }^{[10]}$ 。人侵植物对本地植物群落的影响是植 物人侵研究的重点。例如, Wolf 从群落角度分析了 草木犀上侵对高山草地的影响 ${ }^{[11]}$; Hejda 分析了植 物人侵后群落多样性的变化,认为这种变化源自于 人侵植物与本地植物高度、盖度的不同 ${ }^{[12]}$; Flory 认 为植物人侵后会抑制本地植物生长, 并改变群落结 构 ${ }^{[13]}$ 。小叶章侵人苔原带必将导致苔原带景观的 巨大变化,其对于生态系统的影响亟需深人的研究 和分析。

本文在高光谱及影像分析的基础上,结合 GPS 定位技术揭示小叶章侵人苔原带的演变过程; 通过 野外调查, 对不同侵人强度的斑块进行群落调查及 土壤分析; 探究小叶章侵人苔原带的过程并阐述其 对于苔原带产生的影响。从而为小叶章上侵机理的 研究提供数据支撑; 为小叶章人侵的治理提供科学 依据; 并丰富高山地带植物人侵研究,为全球范围内 存在的高山植被带上移现象提供实证参考。

\section{1 研究区概况}

研究区位于长白山苔原带西坡 $\left(41^{\circ} 58^{\prime}-41^{\circ}\right.$ $\left.59^{\prime}, 127^{\circ} 59^{\prime}-128^{\circ} 01^{\prime}\right)$, 为火山锥体的迎风坡的上 部(海拔 $2000 \mathrm{~m}$ 以上)。研究区温度低, 生长季 (6-9 月份) 日平均气温只有 $5.87{ }^{\circ} \mathrm{C}$ 。降水丰富, 生 长季年均降水量可达 $958.04 \mathrm{~mm}$ 。风力大, 全年平均 风速 $11.7 \mathrm{~m} / \mathrm{s}$, 太阳辐射量较强, 年均 $5.066 \mathrm{MJ} /$ $\mathrm{m}^{2[14]}$; 苔原带物理风化强烈, 地表多为疏松的火山 岩风化物和火山灰等喷发物, 流水侵蚀严重; 主要发 育有石质苔原土及苔原土、灌丛苔原土三类土 壤 ${ }^{[15]}$ 。研究区植被类型为苔原植被, 主要植物有牛 皮杜鹃 (Rhododendron chrysanthum)、宽叶仙女木 (Dryas octopetala var. asiatica)、笃斯越橘(Vaccinium uliginosum)、珠芽苶 (Polygonum viviparum)、长圆叶 柳 (Salix rotundifolia)、长白苔草 (Carex siderosticia)、 大白花地榆 (Sanguisorba stipulata)、雪白委陵菜 (Potentilla nivea)、毛芯老鹳草 (Geranium platyanthum)、 高山红景天 (Rhodiola cretinii) 等 $^{[16]}$ 。与低温、强风 的环境相适应, 本地植物, 如牛皮杜鹃、宽叶仙女木 等, 多匍匐生长, 且生长缓慢; 植物叶片多革质或背 面密生线毛 ${ }^{[17]}$ 。

\section{2 研究材料与方法}

\section{1 研究材料}

本文所用影像数据为 Landsat MSS 1983 年 9 月 22 日 (空间分辨率 $60 \mathrm{~m}$ ) , 以及 Landsat $\mathrm{ETM}^{+} 1999$ 年 9 月 2 日, 2002 年 8 月 25 日, 2006 年 9 月 5 日和 2008 年 8 月 25 日 (空间分辨率均为 $30 \mathrm{~m}$ ) 共 5 期影 像, 选取的影像云量均为 $0 \%$, 而且时相相差很小, 具 有可对比性。影像预处理包括 Landsat $\mathrm{ETM}^{+}$影像去 条带,所选影像条带号 116, 行列号 31, 影像中心为 苔原带, 只在边缘处有少量条带, 因此受条带影响很 小; 并进行几何校正,辐射校正等预处理工作。影像 数据归一化植被指数 (NDVI) 的计算通过 ENVI 4.7 软件实现。气象数据采用天池站(距研究区 $6.2 \mathrm{~km}$ ) 对应 TM 影像年份的 8-9 月份数据。温度取此两个 月的平均值, 降水取此两个月降水总和。

野外实验针对目前小叶章人侵斑块进行植物群 落调查,分析说明小叶章侵人现状及斑块特征, 同时 测度小叶章侵人对于群落生物多样性的影响; 并进 行土壤取样,分析小叶章侵人后对苔原带土壤环境 的影响。

\section{2 研究方法}

2012 年 6-9 月份期间,在长白山苔原带西坡海 拔 2000-2500 m 范围内, 对可见的所有小叶章斑块 进行 GPS 定位, 跟踪记录斑块的数量、面积、周长等 信息。同时,对样地内小叶章斑块进行群落调查,统 计样方内植物的种类、株数、盖度、高度等信息。并 根据小叶章侵人现状, 以小叶章盖度对侵人斑块进 行了分类: 小叶章盖度 $>70 \%$ 的斑块为重度侵人斑 块、小叶章盖度 $70 \%-30 \%$ 的斑块为中度侵人斑块、 小叶章盖度 $<30 \%$ 的斑块为轻度侵人斑块 ${ }^{[18-20]}$ 。同 时选择相邻的环境条件相似的本地牛皮杜鹃群落作 为对照区。本研究利用景观分析软件 Fragstat 3.4 对 
小叶章斑块进行了斑块重要值, 斑块数量, 斑块平均 面积及最大斑块面积等主要指标的分析。并采用 4 种 $\alpha$ 多样性指数测度群落物种的多样性, 以此反映 小叶章人侵对植物群落的影响: Shannon-Wiener 多 样性指数、Pielou 均匀性指数、Margalef's 多样性指 数、Richness 丰富度指数。不同侵人强度下多样性 指数的差异性检验采用单因素方差分析 Tukey HSD 检验。

(1) 应用 ASD Field-Spectral ${ }^{\mathrm{TM}}$ 便携式地物光谱 仪进行光谱采样

测量光谱范围 350-2500 nm, 在 350-1000 nm 抽样间隔为 $1.4 \mathrm{~nm}$, 光谱分辨率为 $3 \mathrm{~nm}$; 在 $1000-$ $2500 \mathrm{~nm}$ 抽样间隔为 $2 \mathrm{~nm}$, 光谱分辨率为 $10 \mathrm{~nm}$ 。 采样时间为 2012 年 8 月 25 日一 9 月 5 日,对应本研 究采用的 Landsat TM 影像时间 (8 月底至 9 月底)。 采样在晴朗无云的天气条件下进行, 于 10:00 至 14:00测定光谱。每 $20 \mathrm{~min}$ 进行 1 次白板优化。光 谱仪探头全视场角为 $25^{\circ}$, 测定光谱时探头垂直向 下，距植物群落冠层的高度为 $1.5 \mathrm{~m} 。 3$ 种植物群 落各测定 10 组共 150 个数据。获得数据后应用 RS3 及 ENVI 软件对数据进行平滑去噪、平均化等处理, 最终得出牛皮杜鹃群落 (原生植被) 、过渡群落( 中 度侵人斑块及轻度侵人斑块) 、小叶章群落 (重度侵 人斑块) 3 种典型群落的光谱曲线, 并计算 NDVI 值, 公式如下:

$$
\mathrm{NDVI}=\left(\rho_{\mathrm{NIR}}-\rho_{R}\right) /\left(\rho_{\mathrm{NIR}}+\rho_{R}\right)
$$

式中, $\rho_{\mathrm{NIR}}$ 为波段 775-900 nm(对应 TM 影像近红外 波段) 范围内的平均值, $\rho_{R}$ 为波段 630-690 nm(对应
TM 影像红波段) 范围内的平均值。

定量区分 3 种典型植物光谱红边特征的红边参 数选择 (1) 红边幅值 $D_{r}$, 即红边 $(680-760 \mathrm{~nm})$ 内最 大的一阶微分值; (2) 红边位置 $\lambda_{r}$, 即最大一阶微分 值对应的波长; (3) 红边面积 $S D_{r}$, 即红边内一阶微 分值的总和。

(2)对基质和三类斑块进行土壤取样。苔原带 土层较薄, 因此本研究对 $0-5 \mathrm{~cm}$ 土层土壤进行取 样,并保证 3 次重复。采用 Hobo 土壤温水自动记录 仪测定 3 种植物群落的土壤含水量变化。土壤性质 的测定主要包括 $\mathrm{pH}$ 值、全氮、速效氮, 以及腐殖质 (包括胡敏酸和富里酸) 等几个主要方面。土壤性质 差异性检验采用单因素方差分析 Tukey HSD 检验。

\section{3 结果}

\section{1 小叶章侵人现状}

表 1 列出了 5 个海拔范围内的小叶章斑块分布 现状。可以看出小叶章在低海拔处的斑块数量虽 小,但面积较大; 高海拔斑块数量多,但面积往往较 小。斑块重要值体现了斑块对景观保持连通的重要 性, 玟块越大, 对景观连通性意义越大。本文以 100 $\mathrm{m}$ 景观距离阈值计算斑块重要值。从变化看, 小叶 章斑块重要值沿海拔逐渐下降, 结合人侵程度, 可以 推断低海拔处的小叶章斑块经过多年的扩张之后已 连接成片,而高海拔处的斑块正处于扩张的阶段。 低海拔处景观与小叶章斑块分布有着紧密的联系, 高海拔处景观受小叶章斑块影响还较小。

表 1 小叶章斑块分布现状

Table 1 Distribution information of $D$. angustifolia patches

\begin{tabular}{|c|c|c|c|c|c|}
\hline $\begin{array}{l}\text { 海拔/m } \\
\text { Elevation }\end{array}$ & $\begin{array}{c}\text { 斑块重要值 } \\
\text { Importance } \\
\text { of patches }\end{array}$ & $\begin{array}{c}\text { 斑块数量 } \\
\text { Patch number }\end{array}$ & $\begin{array}{l}\text { 斑块平均面积 / m }{ }^{2} \\
\text { Mean area of patches }\end{array}$ & $\begin{array}{l}\text { 最大斑块面积/ } \mathrm{m}^{2} \\
\text { The largest patch area }\end{array}$ & $\begin{array}{c}\text { 侵人程度 } \\
\text { Invasive level }\end{array}$ \\
\hline $2040-2080$ & 0.184 & 4 & 2148 & 3509 & 重度 \\
\hline $2100-2140$ & 0.115 & 2 & 1299 & 1847 & 重度 \\
\hline $2140-2180$ & 0.101 & 8 & 537 & 1737 & 重度 \\
\hline $2180-2220$ & 0.089 & 5 & 318 & 411 & 重度 \\
\hline $2220-2260$ & 0.088 & 12 & 490 & 1551 & 中度、轻度 \\
\hline
\end{tabular}

\section{2 小叶章侵人的过程分析}

小叶章为禾本科草本植物, 而牛皮杜鹃属常绿 灌木。根据观察, 8 月底的长白山苔原带已进人秋
季,小叶章叶片已明显变成黄色, 而牛皮杜鹃依然保 持着绿色。光谱曲线的差异证明了这一点。从实测 光谱曲线来看, 3 种典型植物群落的光谱值存在着较 
大差异 (图 1)。特别是在能够反映植物叶绿素浓 度、生物量的红边波段 $(680-760 \mathrm{~nm})$ 上。红边幅值 $D_{r}$ 由牛皮杜鹃群落向小叶章群落逐渐减小, 红边面 积 $S D_{r}$ 也随着不断减小, 同时红边位置 $\lambda_{r}$ 向短波方 向移动。说明进人秋季, 小叶章叶片叶绿素较之牛 皮杜鹃叶片迅速下降,产生了显著的光谱差异。因 此, 通过光谱曲线反演的植被指数能够区分人侵植 物群落与本地植物群落。根据计算, 3 种典型植物群 落的 NDVI 值表现为小叶章群落 <过渡群落<牛皮杜 鹃群落。可见, NDVI 的变化能够反映小叶章侵人牛 皮杜鹃群落的过程。

根据图 2 可见, 1983-2008 年的 25 年间, 经过 GPS 定位的小叶章斑块内部 NDVI 呈现出显著的减 小趋势。自 1999 年开始,斑块的 NDVI 值已经开始 变小,特别是在海拔 $2060 \mathrm{~m}$ 附近的两个较大斑块以 及海拔 $2240 \mathrm{~m}$ 处的几个较小的斑块。NDVI 值大幅 度的减小发生在 21 世纪, 自 2002 年开始,所有斑块 的 NDVI 值均低于 1999 年斑块 NDVI 的最小值。至 2008年, 斑块的 NDVI 值仍然表现为不断下降的趋 势。联系影像对应时间段的温度水分条件(图 3)，
可以看出这5 a长白山苔原带的水热配置条件是逐

\section{— 牛皮杜鹃群落光谱曲线}

$\lambda_{r}=718, D_{r}=0.0116, S D_{r}=0.4931, \mathrm{NDVI}=0.8924$

一一过渡群落光谱曲线

$\lambda_{r}=718, D_{r}=0.0090, S D_{r}=0.4414, \mathrm{NDVI}=0.8120$ 小叶章群落光谱曲线

$\lambda_{r}=700, D_{r}=0.0052, S D_{r}=0.2738, \mathrm{NDVI}=0.7509$

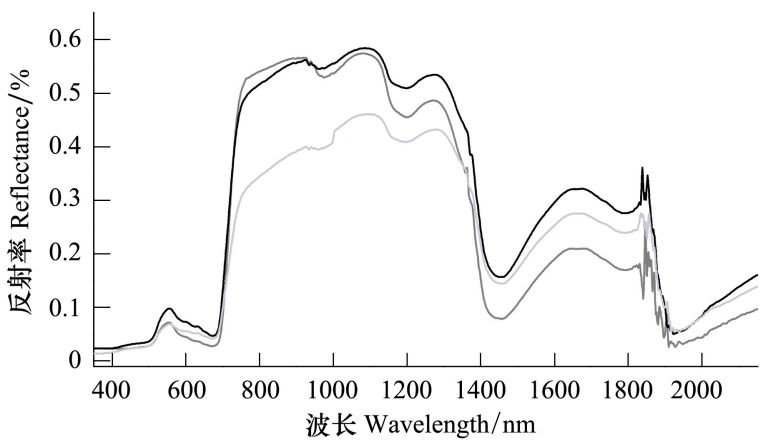

图 1 牛皮杜鹃群落(原生植被)、过渡群落 (中度侵人斑块及轻 度侵人斑块)、小叶章群落 (重度侵人斑块) 3 种典型群落的光谱 曲线

Fig.1 Spectrum curves of native plant community ( $R$. chrysanthum community), transition plant community (invasive patches at low and medium invasive level) and $\boldsymbol{D}$. angustifolia patches (invasive patches at high invasive level)

$\lambda_{r}$ 为红边位置 represents the red edge; $D_{r}$ 为红边幅值 represents the amplitude of the red edge; $S D_{r}$ 为红边面积 represents the red edge area
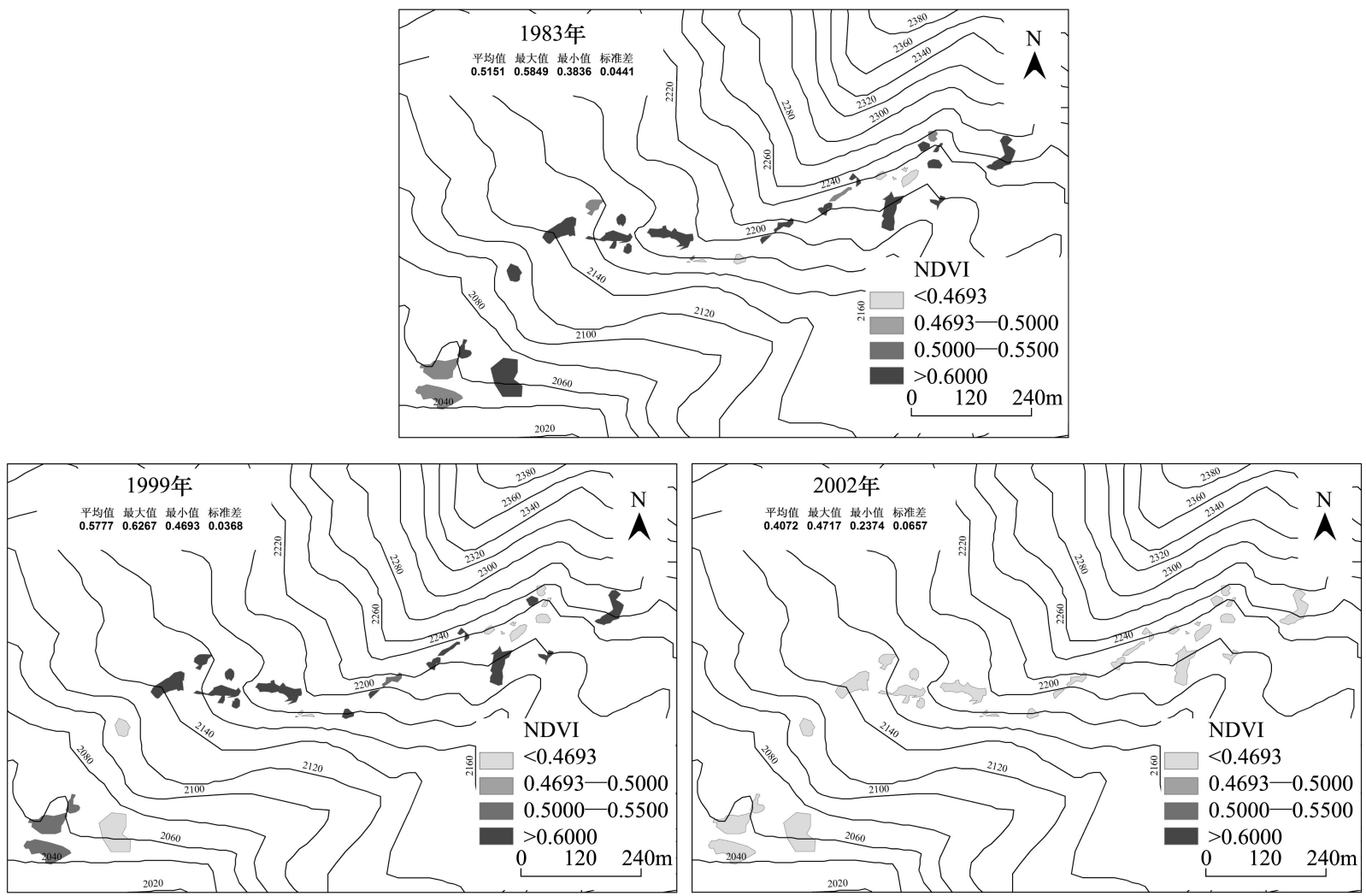

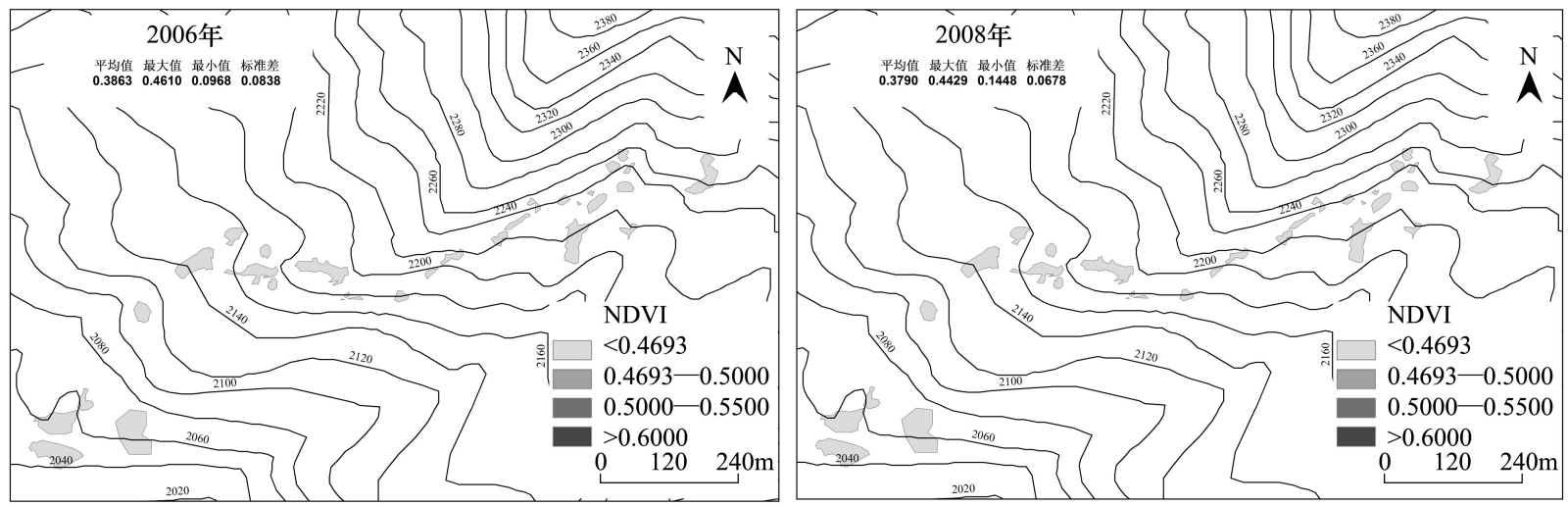

图 2 小叶章斑块 NDVI 多年变化图

Fig.2 Changes in NDVI within the $D$. angustifolia patches

不同字母表示具有显著性差异 $(P<0.05)$

渐改善的,植物群落的长势应更加良好, 从而呈现更 高的绿度值, 即 NDVI 值。然而 1983 年获取的影像 时间为 9 月 22 日,与其他影像获取时间 ( 8 月 25 日一9月 5 日)相比较,其已明显处于深秋季节, 且 水热配置较差, 温度偏高, 降水偏少, 却具备较高的 NDVI 值。这显然说明斑块内原有植物应为具备较 高绿度值的牛皮杜鹃群落。然而伴随着小叶章的侵 人,植物群落发生了明显的变化, 主要表现为绿度值 的不断减小。结合两种植物群落光谱值差异, 可以 看出, 80 年代初, 小叶章还没有形成大规模的侵人, 小叶章侵人牛皮杜鹃群落于 1999 年已经开始, 并通 过种间竞争逐渐获得了群落的主导地位。2000 年 后,侵人的小叶章逐渐替代牛皮杜鹃,形成以自身为 主导的优势植物群落。

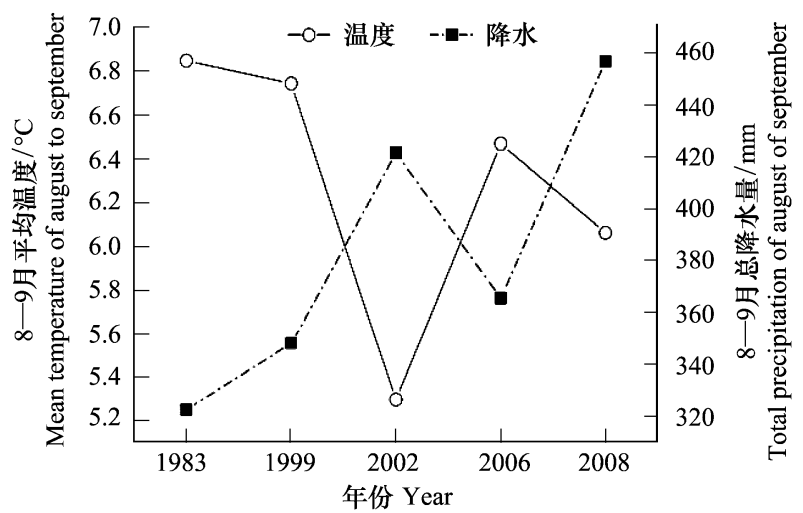

图 3 对应 TM 影像时间段 (8-9 月份) 温度水分条件变化

Fig.3 Variations of temperature and precipitation of August to September corresponding to the Landsat TM images

3.3 小叶章侵人对植物群落的影响

牛皮杜鹃群落为苔原带本地植物群落, 其主要
受到小叶章的侵人影响。从表 2 可以看出,伴随着 小叶章的侵人,植物群落结构发生了显著的变化。 本地植物群落和轻度侵人群落的优势种是牛皮杜 鹃、笃斯越桔等灌木, 草本植物很少; 中度侵人强度 群落的优势种是牛皮杜鹃和小叶章等植物; 而重度 侵人群落的优势种是小叶章、大白花地榆等草本植 物。可以看出,伴随着小叶章的侵人, 灌木数量明显 减少, 草本植物逐渐增多。相对应的, 不同侵人强度 群落植物的生活型也相应改变。另外,群落的高度 也伴随着小叶章的侵人逐渐升高, 这与草本植物的 增多有关。

从图 4 可以看出, 小叶章人侵后对本地植物群 落产生了很大的影响。从 Shannon-Wiener index 指 数变化来看, 从本地牛皮杜鹃群落和轻度人侵斑块 到中度、重度侵人群落的多样性随海拔上升减小; 中 度人侵斑块呈现波动减小的趋势; 而重度侵人斑块 则表现出波动增加后减小的趋势。总体上看, 重度 人侵斑块的多样性要大于轻度人侵斑块。说明伴随 着小叶章的侵人,群落物种数量在不断增加。物种 丰富度指数 (Richness index) 的变化证明了这一点, 且 Richness 指数沿海拔梯度呈现减小的趋势, 说明 海拔对于物种分布有着一定的限制作用, 即对于小 叶章人侵有着一定的抵御作用。伴随着小叶章的侵 人,群落物种数量明显升高。重度人侵斑块的波动 性说明这种人侵使得植物群落结构处于不稳定的状 态。丰富度指数 (Margalef's index) 与 ShannonWiener 指数变化相似, 其在海拔 $2151 \mathrm{~m}$ 以下位置, 轻 度人侵斑块丰富度要小于重度人侵斑块, 在海拔 2 $151 \mathrm{~m}$ 以上两者近似; 总体而言, 中度人侵斑块的 
Margalef's 丰富度指数要大于其他两种群落。证实 了小叶章人侵后, 植物群落的物种数量在不断增加。 均匀度指数 (Evenness index) 表现为重度侵人斑块 大于中度和轻度侵人斑块, 且随海拔上升减小; 结合
Shannon-Wiener 指数和 Richness 指数的变化来看, 伴 随着小叶章的侵人, 群落物种数量增加, 小叶章在群 落中的优势主导地位随海拔上升而不断上升; 在高 海拔处易形成以自身为主导的优势植物群落。

表 2 小叶章三种侵入强度群落中主要植物信息

Table 2 Information of main species of communities at different invasive levels

\begin{tabular}{|c|c|c|c|c|c|c|c|}
\hline $\begin{array}{l}\text { 植物名称 } \\
\text { Species }\end{array}$ & $\begin{array}{c}\text { 高度/cm } \\
\text { Height }\end{array}$ & $\begin{array}{c}\text { 功能型 } \\
\text { Functional } \\
\text { type }\end{array}$ & $\begin{array}{l}\text { 生活型 } \\
\text { Life form }\end{array}$ & $\begin{array}{c}\text { 对照 } \\
\text { Control }\end{array}$ & $\begin{array}{c}\text { 轻度人侵斑块 } \\
\text { Invasive patches } \\
\text { with low level }\end{array}$ & $\begin{array}{c}\text { 中度人侵斑块 } \\
\text { Invasive patches } \\
\text { with medium } \\
\text { level }\end{array}$ & $\begin{array}{c}\text { 重度人侵玟块 } \\
\text { Invasive patches } \\
\text { with high level }\end{array}$ \\
\hline $\begin{array}{l}\text { 雪白委陵菜 } \\
\text { Potentilla nivea }\end{array}$ & $5-25$ & 多年生草本 & 地面芽植物 & & & & + \\
\hline $\begin{array}{l}\text { 毛芯老鹳草 } \\
\text { Geranium platyanthum }\end{array}$ & $30-80$ & 多年生草本 & 地面芽植物 & & & & + \\
\hline $\begin{array}{l}\text { 高山乌头 } \\
\text { Aconitum monanthum }\end{array}$ & $20-40$ & 多年生草本 & 地下芽植物 & & & & + \\
\hline $\begin{array}{l}\text { 藜芦 } \\
\text { Veratrum nigrum L. }\end{array}$ & $50-100 \mathrm{~cm}$ & 多年生草本 & 地下芽植物 & & & & + \\
\hline $\begin{array}{l}\text { 大白花地榆 } \\
\text { Sanguisorba stipulata }\end{array}$ & $50-80$ & 多年生草本 & 地面芽植物 & & & + & + \\
\hline $\begin{array}{l}\text { 长白山荣吾 } \\
\text { Ligularia jamesii }\end{array}$ & $30-60$ & 多年生草本 & 地下芽植物 & & & + & + \\
\hline $\begin{array}{l}\text { 珠芽蓼 } \\
\text { Polygonum viviparum L. }\end{array}$ & $5-8$ & 多年生草本 & 地下芽植物 & & & + & + \\
\hline $\begin{array}{l}\text { 小叶章 } \\
\text { Deyeuxia angustifolia }\end{array}$ & $60-90$ & 多年生草本 & 地面芽植物 & & + & + & + \\
\hline $\begin{array}{l}\text { 长白苔草 } \\
\text { Carex peiktusanii }\end{array}$ & $10-15$ & 多年生草本 & 地上芽植物 & & + & + & + \\
\hline $\begin{array}{l}\text { 高山红景天 } \\
\text { Rhodiola cretinii }\end{array}$ & $6-20$ & 多年生草本 & 地面芽植物 & + & + & + & + \\
\hline $\begin{array}{l}\text { 牛皮杜鹃 } \\
\text { Rhododendronchrysanthum }\end{array}$ & $10-25$ & 常绿灌木 & 中位芽植物 & + & + & + & \\
\hline $\begin{array}{l}\text { 笃斯越桔 } \\
\text { Vaccinium uliginosum }\end{array}$ & $10-15$ & 落叶灌木 & 中位芽植物 & + & + & & \\
\hline $\begin{array}{l}\text { 圆叶柳 } \\
\text { Salix rotundifolia }\end{array}$ & $2-3$ & 矮灌木 & 地上芽植物 & & + & & \\
\hline
\end{tabular}

Control 为对照群落; +表示该物种存在于该植物群落

\section{4 小叶章侵人对土壤的影响}

小叶章人侵对于土壤性质的影响较大。首先, 重度人侵斑块的土壤含水量高于中度人侵斑块及本 地牛皮杜鹃群落下的土壤( 图 5 )。这说明伴随着小 叶章的人侵, 土壤持水能力逐渐升高。这直接影响 了土壤的腐殖质分解过程。从土壤腐殖质含量来看 (表 3 ), 轻度人侵斑块较之重度人侵斑块腐殖质含 量高, 中度人侵群落则表现出最高的腐殖质含量, 3 种斑块的腐殖质含量均低于本地牛皮杜鹃群落。说 明轻度人侵斑块保持了原牛皮杜鹃群落下灌丛苔原 土的特性, 而伴随着小叶章的侵人, 土壤中腐殖质含 量呈现下降的趋势。富里酸是土壤腐殖质的重要组
成部分, 且在 3 种土壤中均大于胡敏酸含量。可以 看出伴随着小叶章的侵人, 土壤富里酸是不断下降 的。胡敏酸则表现为本地牛皮杜鹃群落以及轻度人 侵斑块大于重度人侵斑块。小叶章人侵导致土壤含 水量的增加, 而富里酸的各个价态都能很好的溶解 在水中, 胡敏酸则刚好相反。因此, 随着小叶章的侵 人, 土壤富里酸的含量不断上升。3 种斑块的土壤中 全氮、速效氮的差异并不是很大。伴随着小叶章人 侵强度的增加, 土壤氮的含量不断减小,而速效氮的 含量有略微的增加。土壤 $\mathrm{C} / \mathrm{N}$ 比率都较大, 表明土 壤变化滞后于植被变化。且伴随小叶章的人侵, $\mathrm{C} /$ $\mathrm{N}$ 比率不断下降, 说明小叶章人侵后草本植物对土 壤贡献提升, 土壤草甸化。另外, 各类斑块的土壤均 
呈酸性反应。
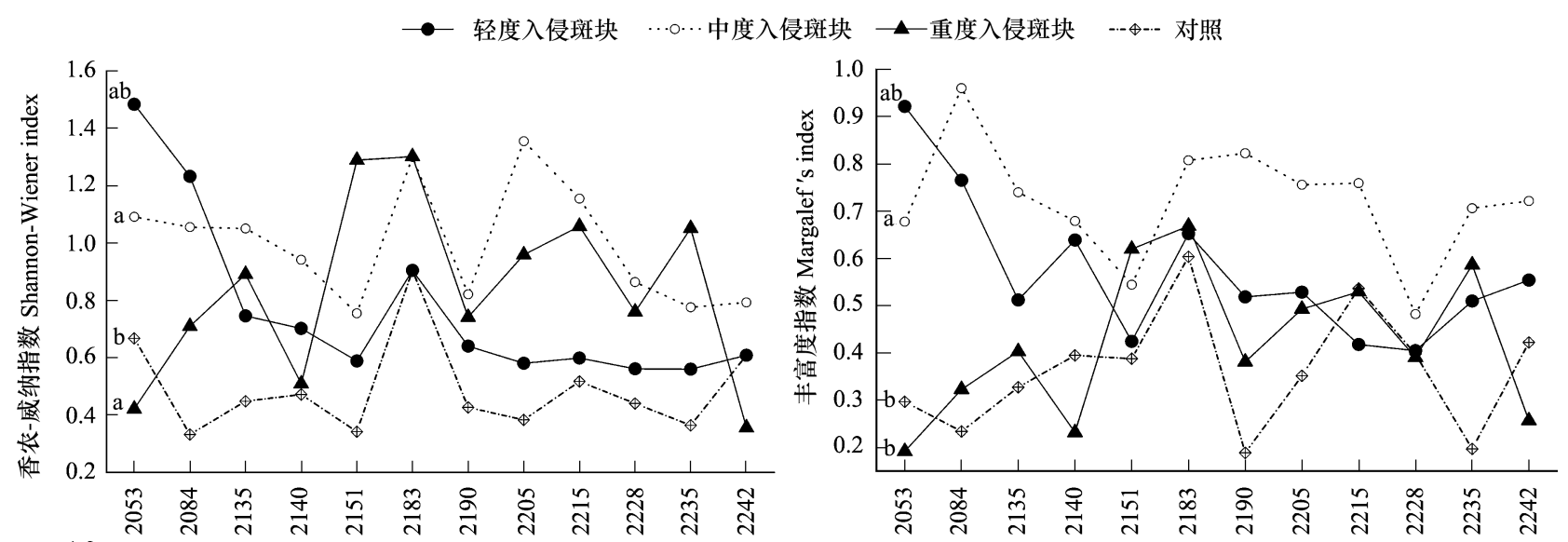

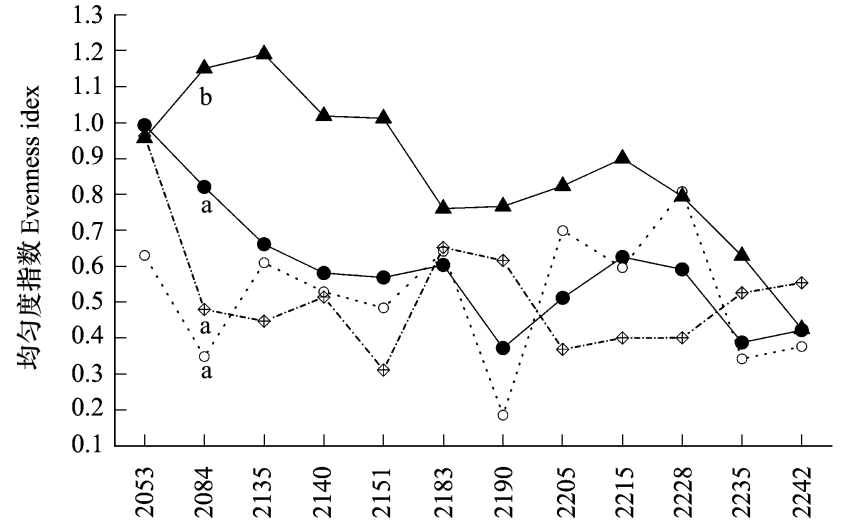

海拔 Elevation/m

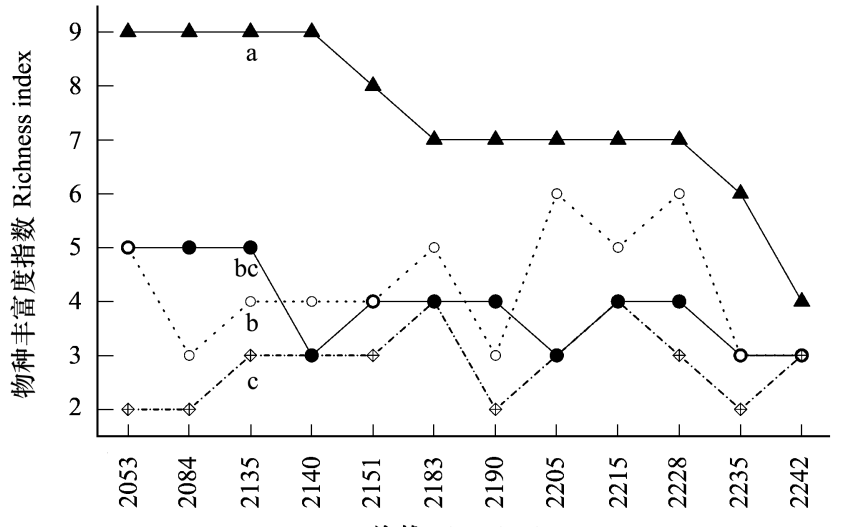

海拔 Elevation/m

图 4 不同侵入强度下植物群落的 $\alpha$ 多样性随海拔的变化

Fig.4 Changes in $\alpha$ biodiversity of the plant communities at different invasive levels Control 为对照群落, 即本地牛皮杜鹃群落; 不同字母表示具有显著性差异 $(P<0.05) ; R$. chrysanthumcommunity is considered as the control plot, which is also the native communities. Different letters mean significantly different $(P<0.05)$

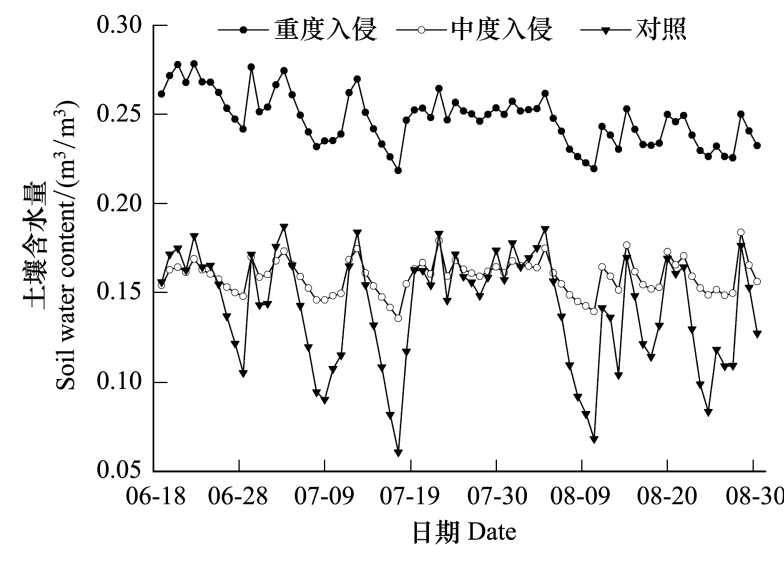

图 5 小叶章中度侵入和重度侵入强度群落以及本地牛皮杜鹃 斑块 (Control) 下土壤含水量的变化 ${ }^{\text {[21] }}$

Fig.5 Changes in soil water contents of medium invasive level patch, high invasive level patch and native community $(R$. chrysanthum community)

土壤深度为 $5 \mathrm{~cm}$; 测量时间为 6 月 18 日一 8 月 30 日

\section{4 结论与讨论}

(1) 目前小叶章已经成功侵人到长白山西坡苔 原带区域。低海拔处的斑块数量小但面积较大;高 海拔处小叶章斑块面积较小但数量较多。低海拔处 的小叶章斑块经过多年的扩张生长之后已连接成片 而高海拔处的斑块正处于扩张的初期阶段。低海拔 处景观与小叶章斑块分布有着紧密的联系,高海拔 处景观受小叶章斑块影响还较小。

(2) 通过影像分析来获取长时间序列的草地植 被变化存在着较大困难。目前,较多研究立足于高 光谱影像数据的分析, 以期获得人侵植物的分布信 息,然而对于人侵变化过程较难给出确定的研究结 果, 这主要受制于早期影像数据的光谱分辨率较低 的限制。另一方面, 长时间序列的影像数据目前主 
表 3 不同侵入强度下植物群落的土壤性质变化

Table 3 Changes in soil properties under the plant communities at different invasive levels

\begin{tabular}{|c|c|c|c|c|c|c|c|}
\hline $\begin{array}{l}\text { 植物群落类型 } \\
\text { Plant community types }\end{array}$ & $\begin{array}{c}\text { 腐殖质 } \\
\text { Soil humus/ } \\
(\mathrm{g} / \mathrm{kg})\end{array}$ & $\begin{array}{c}\text { 胡敏酸 } \\
\text { Humic acid/ } \\
(\mathrm{g} / \mathrm{kg})\end{array}$ & $\begin{array}{c}\text { 富里酸 } \\
\text { Fulvic acid }\end{array}$ & $\begin{array}{l}\text { 碳氮比 } \\
\mathrm{C} / \mathrm{N} \text { ratio }\end{array}$ & $\begin{array}{c}\text { 全氮 } \\
\text { Total } \\
\text { nitrogen/ } \\
(\mathrm{g} / \mathrm{kg})\end{array}$ & $\begin{array}{c}\text { 速效氮 } \\
\text { Available } \\
\text { nitrogen/ } \\
(\mathrm{g} / \mathrm{kg})\end{array}$ & $\mathrm{pH}$ \\
\hline 对照 Control & $97.62 \pm 1.052^{\mathrm{a}}$ & $36.88 \pm 4.91^{\mathrm{a}}$ & $55.16 \pm 2.011^{\mathrm{a}}$ & $20.44 \pm 4.156^{\mathrm{a}}$ & $11.58 \pm 2.301^{\mathrm{a}}$ & $1.22 \pm 0.13^{\mathrm{a}}$ & $4.38 \pm 0.271^{\mathrm{a}}$ \\
\hline $\begin{array}{l}\text { 轻度人侵斑块 } \\
\text { Invasive patches with } \\
\text { low level }\end{array}$ & $96.12 \pm 2.016^{\mathrm{a}}$ & $35.24 \pm 7.21^{\mathrm{ab}}$ & $54.10 \pm 9.24^{\mathrm{b}}$ & $20.56 \pm 3.81^{\mathrm{a}}$ & $11.00 \pm 2.48^{\mathrm{a}}$ & $1.29 \pm 0.09^{\mathrm{a}}$ & $4.52 \pm 0.17^{\mathrm{a}}$ \\
\hline $\begin{array}{l}\text { 中度人侵斑块 } \\
\text { Invasive patches with } \\
\text { medium level }\end{array}$ & $92.78 \pm 4.149^{b}$ & $40.92 \pm 10.51^{\mathrm{a}}$ & $39.58 \pm 12.28^{\mathrm{ac}}$ & $18.36 \pm 2.81^{\mathrm{ab}}$ & $10.42 \pm 2.69^{\mathrm{ab}}$ & $2.38 \pm 0.11^{\mathrm{a}}$ & $4.63 \pm 0.19^{\mathrm{a}}$ \\
\hline $\begin{array}{l}\text { 重度人侵斑块 } \\
\text { Invasive patches with } \\
\text { high level }\end{array}$ & $88.42 \pm 2.811^{\mathrm{ac}}$ & $31.55 \pm 7.58^{b}$ & $33.84 \pm 11.85^{b}$ & $16.49 \pm 3.84^{b}$ & $8.45 \pm 2.10^{\mathrm{b}}$ & $2.93 \pm 0.11^{\mathrm{a}}$ & $4.82 \pm 0.11^{\mathrm{b}}$ \\
\hline
\end{tabular}

土壤深度均为 $5 \mathrm{~cm}$, 数值代表平均值沶准差; 对照为本地牛皮杜鹃群落; 不同字母表示具有显著性差异

要以 Landsat TM 系列数据为主, 此类数据空间及光 谱分辨率较低, 在区分森林植被和草地植被研究中 具有一定的优势, 然而区分草地植被中的不同植物 群落则效果不佳。利用季相差异是区分人侵植物和 本地植物的有效技术方法 ${ }^{[9]}$ 。本研究依据小叶章与 牛皮杜鹃的光谱差异及其反演的植被指数, 探讨小 叶章侵人苔原带的过程。认为小叶章上侵开始于 20 世纪 80 年代末, 进人 21 世纪后逐渐形成稳定的以 小叶章为优势物种的植物群落结构。结合长白山西 坡植被变化的历史过程, 1986 年长白山西坡经历了 一次较强的台风, 在岳桦林带形成了大量的林窗, 目 前林窗中的小叶章生长旺盛。这很可能与其侵人苔 原带有着紧密的联系。同时, 这又进一步印证了 NDVI 值变化的分析结果。

(3) 小叶章侵人苔原带对植物群落的影响较大, 主要表现为植物群落多样性的升高和物种数量的增 加。伴随着小叶章的侵人, 灌木数量明显减少, 草本 植物逐渐增多, 其改变了牛皮杜鹃群落的群落结构, 并通过竞争逐渐替代牛皮杜鹃成为了群落的主导优 势物种, 体现了较强的竞争力。伴随着小叶章的侵 人, 更多的草本植物出现了新的群落中; 群落结构的 改变影响了土壤的理化性质, 小叶章人侵后土壤腐 殖质含量和全氮含量下降, 但土壤养分的高效利用 又进一步推动了小叶章的生长。可见, 土壤的变化 将进一步影响植物群落结构的改变。

(4)长白山西坡小叶章侵人苔原带现象在我国 高山植被研究中是十分独特的, 从植物多样性分析 和土壤理化性质变化来看, 已经对苔原带造成了严
重的生态后果。小叶章的进一步发展必将威胁牛皮 杜鹃等苔原植物的生存发展, 作为我国温带地区仅 有的高山苔原景观也必将因其发生而变化。

小叶章侵人苔原带尚需进一步的实验研究来获 悉其机制。通常植被的变化与生态系统干扰息息相 关,1986 年的台风干扰使得小叶章在林窗中得以大 量繁殖生长, 这无疑为侵人苔原带提供了大量的种 源。同时气候变暖的影响也不可忽视。Lenoir 认为 气候变暖是导致低海拔物种分布范围上移的驱动因 素 ${ }^{[22]}$; Breshears 认为气候变暖将导致高山不同植被 带位置整体上移 ${ }^{[23]}$ 。长白山苔原带气候目前正逐 步变暖 ${ }^{[14]}$, 小叶章侵人苔原带又或许是对于气候变 暖的一种响应。然而北坡尚未发现小叶章侵人苔原 带的现象,两个坡向的气候条件类似,植被变化却有 着如此大的差异, 说明两个坡向的植被演替进程存 在着差异。由此,理解小叶章上侵应从台风干扰、气 候变化、植被演替等多个方面综合研究, 并考虑到这 些要素之间的耦合作用,这尚需长时间序列的野外 观测与调查数据的支持, 从而更为深人的理解温带 高山地区植被垂直带变动的机理, 并进一步解释长 白山植被分布的特殊性。

\section{References:}

[ 1 ] Wearne L J, Morgan J W. Shrub invasion into subalpine vegetation: implications for restoration of the native ecosystem. Plant Ecology, 2006, 183(2) : 361-376.

[2] Krannitz P, Kesting S. Impacts of climate change on the plant communities of alpine ecosystems//Taylo E, Taylor B, eds. Responding to global climate change in British Columbia and Yukon. Ministry of Environment, Lands and Parks, Victoria, B. 
C, 1997.

[ 3 ] Tsuyuzaki S. Wetland development in early stages of volcanic succession. Journal of Vegetation Science, 1997, 8 (3): 353-360.

[ 4 ] Shi P L, Li W H. Boundary form effects of timberline ecotone on colonization of woody plants and timberline dynamics in Changbai Mountain. Acta Ecologica Sinica, 2000, 20 (4): 389-398.

[ 5 ] Qian J J. Vertical Plant Checklist of Changbai Mountain. Changchun: Northeast Normal University Press, 1980: 90-91.

[6] Qian H. Alpine tundra vegetation on the Changbai mountain // Forest Ecological Research vol. 6. Beijing: China Forestry Publishing House, 1992: 72-96.

[ 7 ] Zong S W, Xu J W, Wu Z F. Investigation and mechanism analysis on the invasion of Deyeuxia. angustifolia to tundra zone in western slope of Changbai Mountain. Journal of Mountain Science, 2013, 31(4) : 448-455.

[ 8 ] Bradley B A, Mustard J F. Characterizing the landscape dynamics of an invasive plant and risk of invasion using remote sensing. Ecological Applications, 2006, 16(3) : 1132-1147.

[ 9 ] Walsh S J, Mccleary A L, Mena C F, Shao Y, Tuttle J P, González A, Atkinson R. QuickBird and Hyperion data analysis of an invasive plant species in the Galapagos Islands of Ecuador: Implications for control and land use management. Remote Sensing of Environment, 2008, 112(5) : 1927-1941.

[10] Gao Z G, Zhang L Q. Measuring and analyzing of the multi seasonal spectral characteristics for saltmarsh vegetation in Shanghai. Acta Ecologica Sinica, 2006, 26(3) : 793-800.

[11] Wolf J J, Beatty S W, Carey G. Invasion by sweet clover (Melilotus) in montane grasslands, Rocky Mountain National Park. Annals of the Association of American Geographers, 2003, 93(3) : 531-543.

[12] Hejda M, Pyšek P, Jarošík V. Impact of invasive plants on the species richness, diversity and composition of invaded communities. Journal of Ecology, 2009, 97(3) : 393-403.

[13] Flory S L, Clay K. Non-native grass invasion alters native plant composition in experimental communities. Biological Invasions, $2010,12(5): 1285-1294$.

[14] Zong S W, Wu Z F, Du H B. Variation characteristics of climate change in Changbai Alpine tundra during the growing season in recent 52 years. Arid Zone Research, 2013, 30(1) : 41-49.

[15] Huang X C, Li C H. An analysis on the ecology of alpine tundra landscape of Changbai mountains. Acta Geographica Sinica, 1984, 39(3) : 285- 297.

[16] Qian J J, Zhang W Z. A brief report on the reseatch of the Changbaishan alpine. Journal of Northeast Normal University: Natural Science Edition, 1980, (1) : 51-67.

[17] Pauchard A, Kueffer C, Dietz H, Daehler C C, Alexander J, Edwards P J, Arévalo J R, Cavieres L A, Guisan A, Haider S. Ain't no mountain high enough: plant invasions reaching new elevations. Frontiers in Ecology and the Environment, 2009, 7
(9) : 479-486.

[18] Zhang T R, Huangfu C H, Bai X M, Yang D L, Li G, Lai X, Zhao J N. Effects of Flaveria bidentis invasion on soil nutrient contents and enzyme activities. Chinese Journal of Ecology, 2010, 29(7) : 1353-1358.

[19] Yu X J, Yu D, Lu Z J, Ma K P. A possible plant invasion mechanism-invader restricted native plant by altering the soil microbes community. Chinese Science Bulletin, 2005, 50(9): 896-903.

[20] Guo X H, Ren M X, Ding J Q, Zheng J M. Plant species diversity and its seasonal dynamics in woodland invaded by Solidago Canadensis (Asteraceae). Plant Science Journal, 2011, 29(2) : 149-155.

[21] Zong S W, Wu Z F, Xu J W, Qin L J, Tao Y, Du H B, Meng X J, Li M, Wang L, Dong D J. Invasion of Deyeuxia angustifolia in the Western Slope of Alpine Tundra, Changbai Mountain. Biological Invasions, 2013 (under review).

[22] Lenoir J, Gegout J C, Marquet P A, de Ruffray P, Brisse H. A significant upward shift in plant species optimum elevation during the 20th century. Science, 2008, 320 ( 5884 ): 1768-1771.

[23] Breshears D D, Huxman T E, Adams H D, Zou C B, Davison J E. Vegetation synchronously leans upslope as climate warms. Proceedings of the National Academy of Sciences, 2008, 105 (33) : 11591-11592.

\section{参考文献:}

[ 4] 石培礼, 李文华. 长白山林线交错带形状与木本植物向苔原 侵展和林线动态的关系. 生态学报, 2000, 20(4) : 389-398.

[ 5 ] 钱家驹. 长白山植物垂直分布名录. 长春: 东北师范大学学 报，1980: 90-91.

[ 6 ] 钱宏. 长白山高山冻原植被 // 森林生态系统研究 (第六卷). 北京: 中国林业出版社, 1992: 72-96.

～ 7 ] 宗盛伟, 许嘉魏, 吴正方. 长白山西坡小叶章侵人苔原带调查 与机理分析. 山地学报, 2013, 31(4): 448-455.

[10］高占国, 张利权. 上海盐沼植被的多季相地面光谱测量与分 析. 生态学报, 2006, 26(3): 793-800.

［14］宗盛伟, 吴正方, 杜海波. 近 52a 长白山苔原带生长季气候变 化特征. 干旱区研究, 2013, 30(1): 41-49.

[15] 黄锡畴, 李崇皜. 长白山高山苔原的景观生态分析. 地理学 报, 1984, 39(3) : 285-297.

[16] 钱家驹, 张文仲. 长白山高山冻原植物的调查研究简报. 东北 师大学报: 自然科学版, 1980, (1): 51-67.

[18］张天瑞, 皇甫超河, 白小明, 杨殿林, 李刚, 赖欣, 赵建宁. 黄顶菊人侵对土壤养分和酶活性的影响. 生态学杂志, 2010 , 29(7) : 1353-1358.

[19] 于兴军, 于丹, 卢志军, 马克平. 一个可能的植物人侵机制人侵种通过改变人侵地土壤微生物群落影响本地种的生长. 科学通报, 2005, 50(9): 896-903.

[20] 郭晓辉, 任明迅, 丁建清, 郑景明. 加拿大一枝黄花人侵林地 对植物多样性的影响及其季节变化. 植物科学学报, 2011, 29 (2) : 149-155. 